THE PERIOPERATIVE MANAGEMENT OF A PATIENT UNDERGOING EMERGENCY SURGERY ON

BUPRENORPHINE and NALOXONE FOR CHRONIC PAIN: A CASE REPORT

Luis Tollinche MD, FASA

\author{
Memorial Sloan Kettering Cancer Center, New York, NY
}

\title{
BACKGROUND:
}

- Suboxone is the trade name for buprenorphine and naloxone (4:1 ratio).

Buprenorphine is a semisynthetic opioid with agonist and antagonist activity at the opioid receptor. In the combination form (suboxone), naloxone is added to buprenorphine to prevent misuse and diversion through parenteral/intranasal administration. It is estimated that 36 million people abuse opioids worldwide ${ }^{1}$, and in the US alone, 9.3 million prescriptions for buprenorphine were written ${ }^{2}$. There is a paucity of literature surrounding the perioperative management of patients on suboxone ${ }^{3}$ but case reports have offered suggestions for management of perioperative pain.

\section{CASE DESCRIPTION:} A 52 year old male with history of chronic pain and opioid dependency on suboxone
presented for emergency repair of fractured tibia. He was taking $12 \mathrm{mg}$ bid of suboxone and had a history of notably high narcotic tolerance and opioid requirements including $200 \mathrm{mg}$ morphine per day for remote abdominal surgery. Pt had a history of hypothyroidism, hypertension, reflux, insulin dependent diabetes and metastatic colon cancer with mets to liver and spleen. He was receiving adjuvant chemotherapy after successful resection of colon cancer and presented to urgent care with tibia fracture sustained in a motor vehicle accident. His last dose of suboxone was the morning of surgery. An anesthesia plan was tailored to address the high opioid requirement and the current suboxone use. This plan included attempts to limit reliance on opioid analgesia. The patient was given preoperative gabapentin $300 \mathrm{mg}$. A lumbar epidural at L2-3 was placed and continuous infusion of bupivacaine $0.125 \%$ at $10 \mathrm{ml} / \mathrm{hr}$ was administered. A $1000 \mathrm{mg}$ of IV acetaminophen was given intraoperatively. Postoperatively, the epidural was titrated to patient pain relief using a patient controlled epidural analgesia (PCEA) pump with bupivacaine $0.0625 \%$ with basal rate of $6 \mathrm{ml} / \mathrm{hr}$. The patient was maintained on preoperative dose of suboxone perioperatively. The highest pain score recorded in the patient's postoperative course was 3 out of 10 on the Visual Analog Scale (VAS). Patient was discharged home two days postoperatively.

\section{- SUMMARY:}

Because suboxone is a partial opioid agonist with high affinity for the mu receptor, and naloxone works as an opioid antagonist, patients on suboxone require substantially higher doses of opioids to achieve pain control. These levels of opioids pose increased risk and side effects. Indeed, adequate pain control may not ever be achieved in these patients with conventional opioid management ${ }^{4}$. When these patients present for surgery, conflicting recommendations have included titrating or stopping suboxone administration. But in the emergency setting, preoperative decision regarding suboxone management is not possible. For these patients, multimodal, opioid free anesthesia, should be considered as a safe and effective alternative.

References

1 UNODC. World Drug Report 2012

2 Administration DE. Buprenorphine. DEA. (July 2013) "Buprenorphine" (PDF) DEA. December 2017

3 Bryson EO. The perioperative management of patients maintained on medications used to manage opioid addiction. Current Opinion in 2 Administration
3 Bryson EO. Th
Anesthesiology 2014; 27: 359-64

4 Stern E. Buprenorphine and the anesthesia considerations: a literature review. 2015 